\title{
Managing patients with ICD shocks and programming tachycardia therapies during acute heart failure syndromes
}

\author{
Jason Bradfield • Roderick Tung • Noel G. Boyle • \\ Kalyanam Shivkumar
}

Published online: 31 March 2011

(c) The Author(s) 2011. This article is published with open access at Springerlink.com

\begin{abstract}
We review the pharmacologic, interventional and device programming treatment options for patients with implantable cardioverter-defibrillators who present with acute heart failure and implantable cardioverter-defibrillator shocks.
\end{abstract}

Keywords Acute heart failure - Implantable cardioverterdefibrillator · Shock · Anti-tachycardia pacing

\section{Introduction}

The management of implantable cardioverter-defibrillator (ICD) shocks and the programming of tachycardia therapies during acute heart failure syndromes is a topic of significant clinical importance, yet with limited data to guide evidencebased recommendations. Implantation of ICDs has been standard of care for resuscitated cardiac arrest and unstable ventricular arrhythmias since the 1990s, based on studies such as the Antiarrhythmics versus Implantable Defibrillators (AVID) trial $[1,2,3]$. Implantation of ICDs for primary prevention of sudden cardiac death in patients with left ventricular dysfunction became widely accepted after the MADIT II and SCD-HeFT studies were published in 2002 and 2005, respectively [4, 5].

Previous studies have shown that patients who receive appropriate ICD therapy are at higher risk for heart failure hospitalizations and mortality [6]. However, for ICD

J. Bradfield $(\bowtie) \cdot$ R. Tung $\cdot$ N. G. Boyle $\cdot$ K. Shivkumar UCLA Cardiac Arrhythmia Center, Ronald Reagan UCLA Medical Center, David Geffen School of Medicine at UCLA, A2-237 CHS, 650 Charles E. Young Drive South, Los Angeles, CA 90095-1679, USA

e-mail: JBradfield@mednet.ucla.edu shocks occurring in the setting of acute heart failure, decisions regarding ICD programming as well as medical and interventional therapy are often based on small studies, expert opinion or personal experience within the cardiac electrophysiology community.

\section{Medical therapy}

Arrhythmias and ICD therapies in cardiomyopathy patients are often related to heart failure exacerbation and associated volume overload. ICDs with heart failure monitoring capabilities, such as intrathoracic impedance monitoring (Optivol, Medtronic, Minneapolis, MN), often show correlation between arrhythmias and volume overload episodes (Fig. 1). Aggressive treatment of volume overload and optimization of heart failure treatments, including beta blockers, angiotensinconverting enzyme (ACE) inhibitors, and aldosterone antagonists is critical. Afterload reduction and diuresis can decrease left ventricular (LV) wall stress and positively impact the arrhythmic substrate, and may also increase cardiac output sufficiently to avoid the need for inotropic support. These and other beneficial effects probably contribute to the decreased frequency of supraventricular and ventricular arrhythmias seen in one study of ACE inhibitor therapy [7].

After correcting volume overload, titrating up to the maximum tolerated beta blocker dose is an essential medical intervention. Besides reducing hospitalizations and mortality, higher doses of beta blockers appear from the MADIT-II trial to decrease the frequency of ventricular tachycardia (VT) and ventricular fibrillation (VF) requiring ICD shocks [8].

There is some concern that high-dose beta blockers may lead to more ventricular pacing, resulting in dyssynchrony and possibly a further decrease in ventricular function. 
Fig. 1 Atrial arrhythmias associated with decompensated heart failure. a Decreased intrathoracic impedance from a Medtronic ICD associated with acute heart failure exacerbations. b Multiple atrial tachyarrhythmias associated with most recent episode

\begin{tabular}{|c|c|c|c|c|}
\hline Treated VTNF & 3 episodes & V. Pacing & $100.0 \%$ & Lower Rate \\
\hline AT/AF & 0 episodes & Atrial Pacing & $100.0 \%$ & Upper Rate \\
\hline Time in AT/AF & $<0.1 \mathrm{hr} /$ day $(<0.1 \%)$ & & & Battery \\
\hline
\end{tabular}

Observations (1) (21-Sep-2009 to 25-Sep-2009)

- Possible fluid accumulation: exceeded OptiVol Threshold, 12-May-2009 -- ongoing.

OptiVol Fluid Trends (Jul-2008 to Sep-2009)

OptiVol fluid index is an accumulation of the difference between the daily and reference impedance.

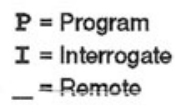

I

I P

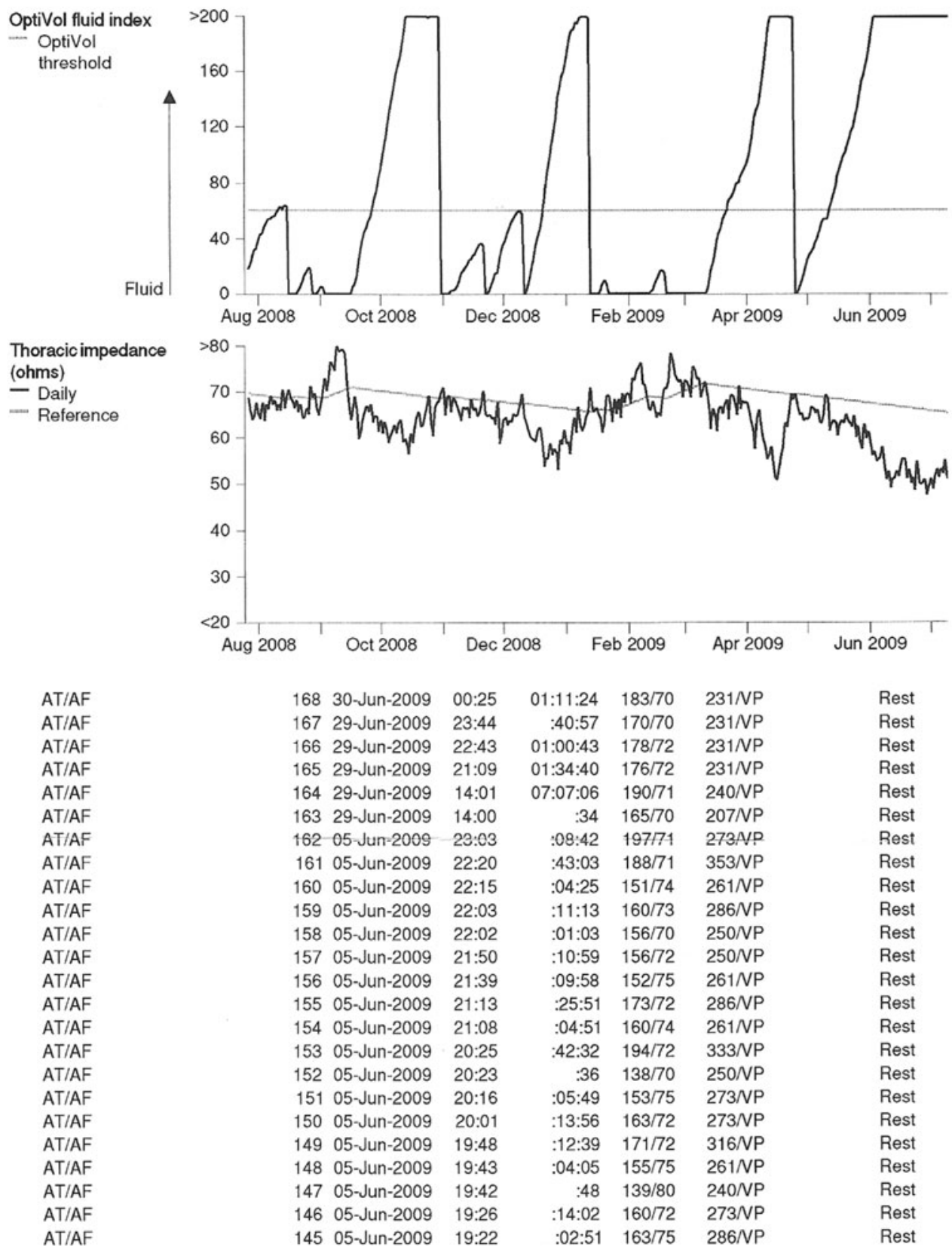


However, in the acute setting, the focus should be on the management of ventricular arrhythmias and patient symptoms, including shocks. In the longer term, if optimal beta blocker dose results in obligate univentricular pacing, consideration can be given to upgrading to a cardiac resynchronization (CRT) device for improved ventricular synchrony.

Although ICD therapy is life-saving, patients presenting with recurrent ICD therapy and no reversible cause frequently require antiarrhythmic drugs to decrease the frequency of shocks. The primary indication for antiarrhythmic drug therapy in ICD patients is VT. However, inappropriate shocks due to rapid supraventricular arrhythmias, can account for up to $27 \%$ of all shocks delivered to ICD patients based on data from SCD-HeFT [9]. Such inappropriate shocks were also associated with increased mortality in this population. Aggressive treatment of supraventricular arrhythmias is important as well.

In the presence of underlying cardiomyopathy, both ischemic and non-ischemic, the choice of antiarrhythmic medications is limited. Data from the CAST trial [10] demonstrated increased mortality associated with the use of class IC agents such as flecainide in the treatment of ventricular ectopy in patients with prior myocardial infarction. Sotalol is a class III agent not recommended in the setting of severe cardiomyopathy based on data from studies such as the SWORD trial [11]. However, it is still frequently used as a second line agent if an ICD is already present. A study by Pacifico and colleagues demonstrated a significant reduction in frequency of shocks in patients treated with sotalol [12]. Furthermore, sotalol may decrease the defibrillation threshold [13], and therefore may be a reasonable choice in patients requiring antiarrhythmic therapy who also demonstrate elevated defibrillation threshold.

Studies on amiodarone and dofetilide, both class III agents, show no evidence of increased mortality in heart failure patients. A recent meta-analysis demonstrated a statistically significant decrease in sudden cardiac death (SCD) and cardiovascular death in patients treated with amiodarone [14]. However, there is no evidence suggesting decreased all-cause mortality with amiodarone therapy from large controlled trials [5]. Amiodarone added to a beta blocker has been shown to significantly decrease ICD shocks compared to beta blocker alone or sotalol [15]. There is appropriate concern regarding amiodarone use in younger patients due to the risk of long-term side effects.

Dofetilide may be an alternative based on the DIAMOND-CHF study [16]. In this study, the dofetilide group had fewer hospitalizations as well as improved rhythm control in the subset of patients with atrial fibrillation. Torsades de pointes did occur in $3.3 \%$ of patients in the dofetilide group versus none in the placebo group, so this drug may not be appropriate in patients without a previously placed ICD. Due to its renal clearance, use of this medication is often limited by renal insufficiency, and the requirement for in-hospital initiation of the drug is another significant limitation.

Dronedarone is a new antiarrhythmic drug chemically similar to amiodarone, but lacking the iodine moiety appears to have less thyroid and pulmonary toxicity. It is contraindicated in the setting of severe heart failure based on the results of the ANDROMEDA study, which demonstrated an increased mortality due to worsening heart failure in the treatment group [17]. However, it was shown to decrease hospital admissions and overall mortality in patients with atrial fibrillation, and mild to moderate heart failure in the ATHENA trial [18].

\section{Interventional therapy}

In the ischemic cardiomyopathy population, ischemia may exacerbate acute heart failure and associated arrhythmias. Prompt assessment and treatment of unstable or flowlimiting coronary stenosis should be undertaken. Acute ischemia is an uncommon cause of monomorphic VT, which is more commonly related to reentry associated with ventricular scar from chronic myocardial infarction or fibrosis from underlying non-ischemic cardiomyopathy. Acute ischemia more commonly causes polymorphic VT or ventricular fibrillation. However, if the ischemia causes worsening heart failure and volume overload, it can lead to increased frequency of all types of ventricular arrhythmias and therefore should be treated aggressively.

Other non-device-related interventions can also be helpful in the setting of recurrent ICD shocks during an acute heart failure exacerbation. Intra-aortic balloon counterpulsation may help reduce afterload, improve coronary perfusion, and relieve acute ischemia, aiding the stabilization of recurrent arrhythmias.

Patients admitted with an acute heart failure exacerbation and recurrent ICD shocks resistant to medical and invasive interventions may require intubation and sedation, both for patient comfort and to decrease the sympathetic surge associated with ventricular arrhythmias. The potential role of the sympathetic nervous system in the initiation and maintenance of ventricular arrhythmias must be considered [19, 20]. Schwartz and colleagues [21, 22, 23] demonstrated that left cardiac sympathetic denervation increases ventricular refractoriness and raises ventricular fibrillation threshold. Deep sedation may beneficially decrease the elevated adrenergic tone seen in this patient population. Other potential treatment options that reduce cardiac sympathetic stimulation are still being assessed, including thoracic epidural anesthesia and left cardiac sympathetic denervation $[24,25]$. These interventions are 
potential future treatment options with promising early results.

\section{Device programming}

Initial ICD management and programming in the setting of acute heart failure should involve assessment of the system to ensure appropriate device and lead function, and to rule out lead fracture, insulation defects, or dislodgement. Stored events should be assessed to determine if appropriate therapies were delivered for ventricular arrhythmias, or if inappropriate shocks resulted from supraventricular tachycardia (SVT), T wave or QRS double counting, electromagnetic or myopotential oversensing, or noise such as from a loose set screw or lead fracture. Once appropriate device function has been confirmed, the arrhythmia events can be analyzed to guide further decisions on programming and treatment options.

Patients implanted with an ICD for primary prophylaxis of sudden cardiac death are often programmed with empiric VT and VF zones based on age and physician preference. Patients with significant ventricular scar, especially those taking antiarrhythmic drugs, can develop relatively slow VT which may fall outside the selected VT detection and treatment zones.

When such a scenario is identified, a reasonable first response is to reprogram the VT zone to a longer cycle length to ensure therapy for the clinical tachycardia. If the tachycardia is hemodynamically tolerated, attempts should be made to treat with anti-tachycardia pacing (ATP) as initial therapy to avoid shocks. Further, the number of ventricular beats in a given zone needed to define a detection of VT episode should be high enough to avoid treating non-sustained events.

It is still debated whether ICD shocks are simply a marker of worsening underlying cardiomyopathy, or whether the shock itself directly contributes to worsened outcomes. There are data showing myocardial damage from ICD shocks [26, 27]. Further, a recent analysis by Sweeney and colleagues[28] reviewing device therapy trials found that patients receiving shocks compared to ATP had increased mortality after controlling for other known risk factors, suggesting that the shock itself contributed to increased mortality. In combination with previous evidence from MADIT-II and SCD-HeFT showing increased mortality after appropriate shocks [6, 9, 29], this suggests that aggressive programming of ATP in the fast VT zone as in the PAINFREE [30] and PAINFREE II trials [31] is safe and reasonable. In a recent study [32], Bhavnani and colleagues used multivariate analysis to compare shocks for device testing with shocks for clinical arrhythmias. Although there was no increased mortality associated with shocks done to test device sensing and defibrillation threshold (DFT), mortality was higher in patients with appropriate shocks, suggesting that the underlying substrate plays a significant role in outcomes and not simply the shock itself.

While there is evidence that ICD shocks can be deleterious to cardiac function, one can also make the argument that clinical VT unresponsive to previous ATP therapy may be better treated with immediate shock. If ATP is not successful, the cumulative time spent in VT will increase, and this may also predict worse outcomes [28]. Therefore, for patients that do not respond to ATP for a given sustained tachyarrhythmia, an immediate shock may be the best treatment option.

Results of the DAVID trial [33] demonstrated that high rates of univentricular pacing increased the combined endpoint of death or hospitalization for heart failure. Given this data, devices should be programmed to minimize unnecessary ventricular pacing. Programming changes, including decreasing base pacing rate and increasing atrioventricular (AV) interval in patients with dual chamber devices should be considered. This is of particular importance if device interrogation demonstrates that an increase in ventricular pacing correlates with the heart failure episode. This must of course be considered along with the patient's tolerance of slower ventricular rates. If increased need for ventricular pacing is due to progression of underlying conduction system disease or is a response to necessary high-dose beta blockade, the addition of a coronary sinus lead for more optimal intraventricular synchrony with biventricular pacing should be considered.

Patients frequently undergo defibrillation threshold testing (DFT) at or near the time of ICD implantation to assess detection and therapy for ventricular fibrillation (VF). While DFT testing remains standard for both primary and secondary prevention device implants, many cardiac electrophysiologists are now omitting DFT testing for primary prevention patients. This is based on large part of published trials demonstrating high defibrillation success rates with newer devices (97.8\% in the SCD-HeFT trial) and a small but concerning risk associated with DFT testing itself. In addition, the correlation between defibrillation threshold at implantation (prolonged anesthesia, supine position, induced VF), and real-world clinical VT or VF is unclear. In long-term follow-up, initial shocks for clinical ventricular arrhythmias had a success rate of $80-100 \%$ regardless of implant DFT [34]. While infrequent, patients with adequate safety margin DFT at implant testing (usually 10 joules), may develop recurrent ventricular arrhythmias refractory to ICD therapies in the setting of acute heart failure. Management of these cases necessitates aggressive medical management of the acute heart failure and volume overload with consideration for repeat DFT 
testing and possible ICD system revision, prior to discharge to ensure successful therapy in the future.

Unsuccessful defibrillation after a clinical ventricular arrhythmia may require changes to the defibrillator system. Non-invasive options include repeat DFT testing utilizing alternative shocking vectors, which in an individual patient may provide a lower DFT. Invasive options include addition of a new RV pace/sense lead if sensing of VF is the issue, or addition of a new RV shocking lead if the current lead is dysfunctional or in a suboptimal position. Addition of a subcutaneous array, SVC coil, or azygous vein lead [35] may also be considered to alter the shocking vector and include more of the left ventricle (LV) in the shocking field.

\section{Evaluation of device proarrhythmia}

Biventricular ICDs and pacemakers have been demonstrated to improve NYHA functional class, decrease heart failure hospitalizations, and decrease mortality in properly selected patients [36, 37]. However, case reports and case series have demonstrated the potential proarrhythmic effects of biventricular devices [38, 39]. These events are relatively rare, and proposed mechanisms include increased dispersion of refractoriness, prolonged QT interval, and atypical autonomic response. The LV lead may induce premature ventricular beat triggers or activate scar-related regions of slow conduction to facilitate reentry. Such

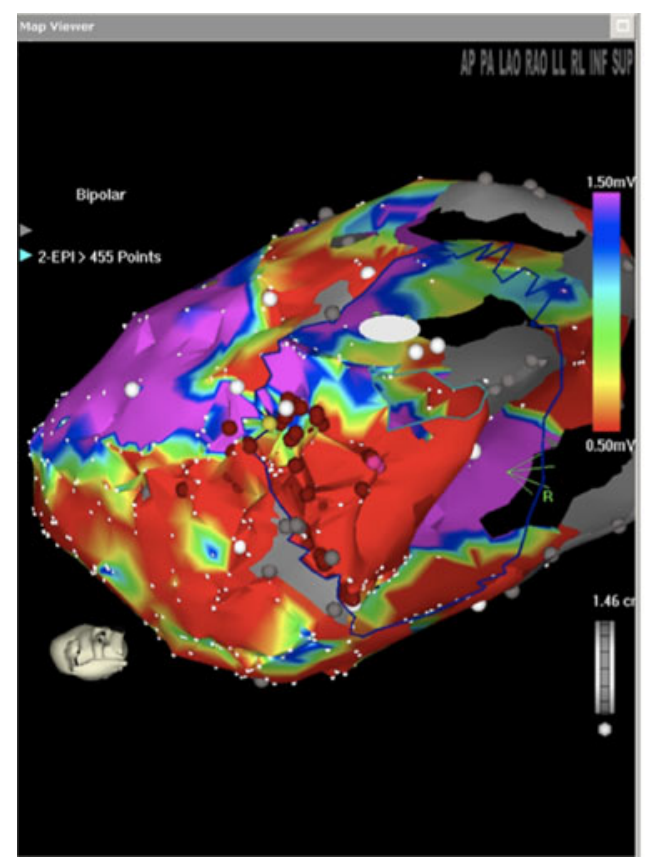

Fig. 2 Combined endocardial and epicardial mapping (left) of nonischemic substrate presenting with VT storm. Red dots on epicardial map (right) created with CARTO electroanatomical atypical responses are infrequent and there are no clear predictors of such a response. However, if a patient presents with heart failure and ventricular arrhythmias after a recent biventricular device implantation, it is reasonable to consider temporarily discontinuing $\mathrm{LV}$ pacing to determine if this will decrease arrhythmic events, which has been demonstrated in some case series [40].

\section{Catheter ablation}

Catheter ablation of VT is moving from a palliative procedure to being used as an earlier preemptive treatment strategy. Recent studies showing improved clinical efficacy (up to $75 \%$ success at 1 year) and acceptable complication rates given the high-risk substrate, include the Multicenter Thermocool Ventricular Ablation trial [41] and the Substrate Mapping and Ablation in Sinus Rhythm to Halt Ventricular Tachycardia trial (SMASH VT) [42]. This evolving role for VT ablation is reflected in the recently published EHRA/HRS Expert Consensus on Catheter Ablation of Ventricular Arrhythmias [43]. While acute heart failure admission was not an exclusion criterion for THERMOCOOL and SMASH-VT, no ablation studies to date have sought to enroll patients specifically in the setting of acute heart failure [44].

It should be recognized that prolonged ablation procedures in the setting of acute heart failure may substantially increase peri-procedural risks due to prolonged supine

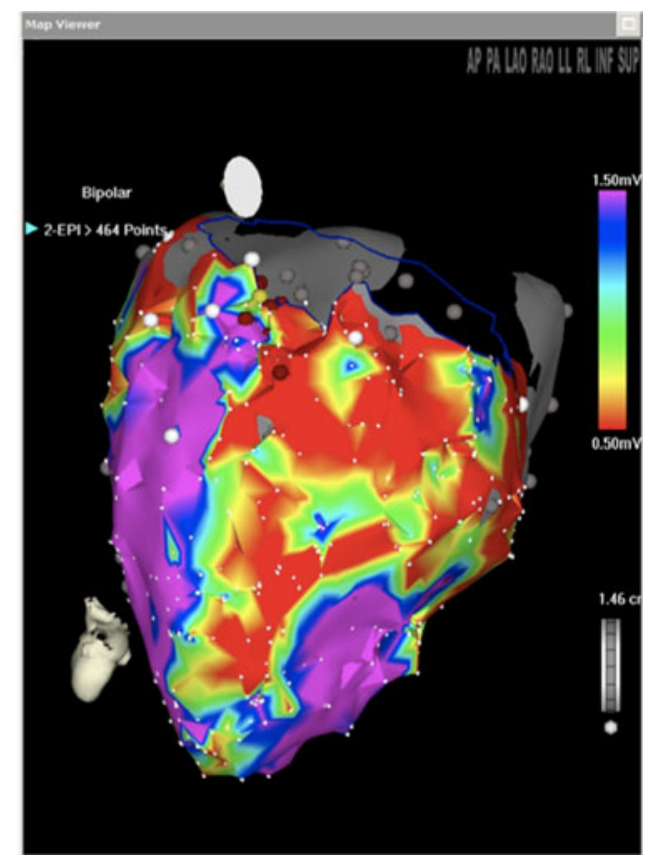

mapping system (Biosense Webster, Diamond Bar, CA) represent ablation lesions at the site of origin of VT 
Fig. 3 AVNRT interpreted as ventricular tachycardia and treated with anti-tachycardia pacing

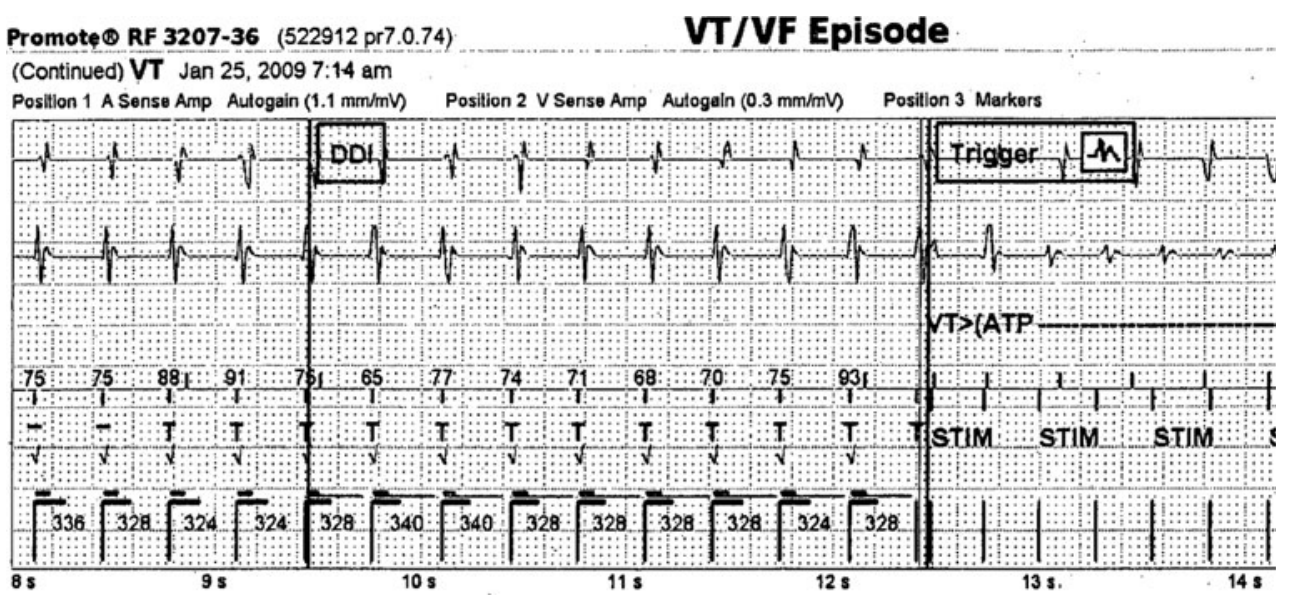

position, protracted anesthesia, and potential volume loading associated with externally irrigated ablation catheters. Therefore, optimization of volume status is essential prior to consideration for VT ablation. In patients with electrical storm which persists despite aggressive management of acute heart failure and antiarrhythmic drug therapy, substrate-based ablation of unstable VT in sinus rhythm guided by electroanatomic mapping systems has been demonstrated to be effective for preventing arrhythmic recurrence [44, 45] (Fig. 2).

Ablation should also be considered when recurrent supraventricular arrhythmias other than atrial fibrillation cause inappropriate ICD therapies. Reentrant arrhythmias such as AV nodal reentrant tachycardia or atrial flutter can occasionally be interpreted as VT or VF by the ICD and lead to inappropriate shocks (Fig. 3). Such rhythms can be difficult to manage medically and have a high cure rate with catheter ablation.

Atrial fibrillation (AF) frequently coexists with ventricular arrhythmias in the cardiomyopathy population. Atrial fibrillation with rapid ventricular rates can lead to ICD shocks despite algorithms meant to differentiate it from VT. Use of a dual chamber device and various atrial fibrillation discrimination algorithms can help but are not fail-safe. When medical therapy fails, consideration can be given to atrial fibrillation ablation. If the AF is refractory to ablation or the patient is not a candidate, and the rate cannot be adequately controlled, then AV nodal ablation with biventricular pacing is an alternative [46].

\section{Conclusion}

Responding to ICD shocks and programming ICD therapies in the setting of acute heart failure involves a combination of medical, interventional, and device-based interventions. Cardiac electrophysiologists and heart failure specialists must work in collaboration to optimize the underlying substrate, treat precipitating factors and program the patient's device to ensure successful therapy while minimizing the number of ICD shocks.

Open Access This article is distributed under the terms of the Creative Commons Attribution Noncommercial License which permits any noncommercial use, distribution, and reproduction in any medium, provided the original author(s) and source are credited.

\section{References}

1. A comparison of antiarrhythmic-drug therapy with implantable defibrillators in patients resuscitated from near-fatal ventricular arrhythmias (1997) The antiarrhythmics versus implantable defibrillators (AVID) investigators. N Engl J Med 337(22):1576-1583

2. Kuck KH, Cappato R, Siebels J, Ruppel R (2000) Randomized comparison of antiarrhythmic drug therapy with implantable defibrillators in patients resuscitated from cardiac arrest: the cardiac arrest study Hamburg (CASH). Circulation 102(7):748-754

3. Connolly SJ, Gent M, Roberts RS, Dorian P, Roy D, Sheldon RS, Mitchell LB, Green MS, Klein GJ, O'Brien B (2000) Canadian implantable defibrillator study (CIDS): a randomized trial of the implantable cardioverter defibrillator against amiodarone. Circulation 101(11):1297-1302

4. Moss AJ, Zareba W, Hall WJ, Klein H, Wilber DJ, Cannom DS, Daubert JP, Higgins SL, Brown MW, Andrews ML (2002) Prophylactic implantation of a defibrillator in patients with myocardial infarction and reduced ejection fraction. $\mathrm{N}$ Engl $\mathrm{J}$ Med 346(12):877-883

5. Bardy GH, Lee KL, Mark DB, Poole JE, Packer DL, Boineau R, Domanski M, Troutman C, Anderson J, Johnson G, McNulty SE, Clapp-Channing N, Davidson-Ray LD, Fraulo ES, Fishbein DP, Luceri RM, Ip JH (2005) Amiodarone or an implantable cardioverter-defibrillator for congestive heart failure. N Engl J Med 352(3):225-237

6. Goldenberg I, Moss AJ, Hall WJ, McNitt S, Zareba W, Andrews ML, Cannom DS (2006) Causes and consequences of heart failure after prophylactic implantation of a defibrillator in the multicenter automatic defibrillator implantation trial II. Circulation 113(24):2810-2817

7. Domanski MJ, Exner DV, Borkowf CB, Geller NL, Rosenberg Y, Pfeffer MA (1999) Effect of angiotensin converting enzyme inhibition on sudden cardiac death in patients following acute myocardial infarction. A meta-analysis of randomized clinical trials. J Am Coll Cardiol 33(3):598-604 
8. Brodine WN, Tung RT, Lee JK, Hockstad ES, Moss AJ, Zareba W, Hall WJ, Andrews M, McNitt S, Daubert JP (2005) Effects of beta-blockers on implantable cardioverter defibrillator therapy and survival in the patients with ischemic cardiomyopathy (from the multicenter automatic defibrillator implantation trial-II). Am J Cardiol 96(5):691-695

9. Poole JE, Johnson GW, Hellkamp AS, Anderson J, Callans DJ, Raitt MH, Reddy RK, Marchlinski FE, Yee R, Guarnieri T, Talajic M, Wilber DJ, Fishbein DP, Packer DL, Mark DB, Lee KL, Bardy GH (2008) Prognostic importance of defibrillator shocks in patients with heart failure. N Engl J Med 359(10):1009-1017

10. Echt DS, Liebson PR, Mitchell LB, Peters RW, Obias-Manno D, Barker AH, Arensberg D, Baker A, Friedman L, Greene HL et al (1991) Mortality and morbidity in patients receiving encainide, flecainide, or placebo the cardiac arrhythmia suppression trial. N Engl J Med 324(12):781-788

11. Waldo AL, Camm AJ, de Ruyter H, Friedman PL, MacNeil DJ, Pauls JF, Pitt B, Pratt CM, Schwartz PJ, Veltri EP (1996) Effect of d-sotalol on mortality in patients with left ventricular dysfunction after recent and remote myocardial infarction. The sword investigators. Survival with oral d-sotalol. Lancet 348(9019):7-12

12. Pacifico A, Hohnloser SH, Williams JH, Tao B, Saksena S, Henry PD, Prystowsky EN (1999) Prevention of implantable-defibrillator shocks by treatment with sotalol. d,l-sotalol implantable cardioverter-defibrillator study group. N Engl J Med 340(24): 1855-1862

13. Hohnloser SH, Dorian P, Roberts R, Gent M, Israel CW, Fain E, Champagne J, Connolly SJ (2006) Effect of amiodarone and sotalol on ventricular defibrillation threshold: the optimal pharmacological therapy in cardioverter defibrillator patients (OPTIC) trial. Circulation 114(2):104-109

14. Piccini JP, Berger JS, O'Connor CM (2009) Amiodarone for the prevention of sudden cardiac death: a meta-analysis of randomized controlled trials. Eur Heart J 30(10):1245-1253

15. Connolly SJ, Dorian P, Roberts RS, Gent M, Bailin S, Fain ES, Thorpe K, Champagne J, Talajic M, Coutu B, Gronefeld GC, Hohnloser SH (2006) Comparison of beta-blockers, amiodarone plus beta-blockers, or sotalol for prevention of shocks from implantable cardioverter defibrillators: the OPTIC Study: a randomized trial. JAMA 295(2):165-171

16. Torp-Pedersen C, Moller M, Bloch-Thomsen PE, Kober L, Sandoe E, Egstrup K, Agner E, Carlsen J, Videbaek J, Marchant B, Camm AJ (1999) Dofetilide in patients with congestive heart failure and left ventricular dysfunction. Danish investigations of arrhythmia and mortality on dofetilide study group. N Engl J Med 341(12):857-865

17. Kober L, Torp-Pedersen C, McMurray JJ, Gotzsche O, Levy S, Crijns H, Amlie J, Carlsen J (2008) Increased mortality after dronedarone therapy for severe heart failure. N Engl J Med 358(25):2678-2687

18. Hohnloser SH, Crijns HJ, van Eickels M, Gaudin C, Page RL, TorpPedersen C, Connolly SJ (2009) Effect of dronedarone on cardiovascular events in atrial fibrillation. N Engl J Med 360(7):668-678

19. Rubart M, Zipes DP (2005) Mechanisms of sudden cardiac death. J Clin Invest 115(9):2305-2315

20. Vaseghi M, Shivkumar K (2008) The role of the autonomic nervous system in sudden cardiac death. Prog Cardiovasc Dis 50(6):404-419

21. Schwartz PJ, Verrier RL, Lown B (1977) Effect of stellectomy and vagotomy on ventricular refractoriness in dogs. Circ Res 40(6):536-540

22. Schwartz PJ, Stone HL, Brown AM (1976) Effects of unilateral stellate ganglion blockade on the arrhythmias associated with coronary occlusion. Am Heart J 92(5):589-599
23. Schwartz PJ, Stone HL (1979) Effects of unilateral stellectomy upon cardiac performance during exercise in dogs. Circ Res 44(5):637-645

24. Mahajan A, Moore J, Cesario DA, Shivkumar K (2005) Use of thoracic epidural anesthesia for management of electrical storm: a case report. Heart Rhythm 2(12):1359-1362

25. Bourke T, Vaseghi M, Michowitz Y, Sankhla V, Shah M, Swapna N, Boyle NG, Mahajan A, Narasimhan C, Lokhandwala Y, Shivkumar K (2010) Neuraxial modulation for refractory ventricular arrhythmias. Value of thoracic epidural anesthesia and surgical left cardiac sympathetic denervation. Circulation

26. Hurst TM, Hinrichs M, Breidenbach C, Katz N, Waldecker B (1999) Detection of myocardial injury during transvenous implantation of automatic cardioverter-defibrillators. J Am Coll Cardiol 34(2):402-408

27. Runsio M, Kallner A, Kallner G, Rosenqvist M, Bergfeldt L (1997) Myocardial injury after electrical therapy for cardiac arrhythmias assessed by troponin- $\mathrm{T}$ release. Am J Cardiol 79(9):1241-1245

28. Sweeney MO, Sherfesee L, DeGroot PJ, Wathen MS, Wilkoff BL (2010) Differences in effects of electrical therapy type for ventricular arrhythmias on mortality in implantable cardioverterdefibrillator patients. Heart Rhythm 7(3):353-360

29. Daubert JP, Zareba W, Cannom DS, McNitt S, Rosero SZ, Wang P, Schuger C, Steinberg JS, Higgins SL, Wilber DJ, Klein H, Andrews ML, Hall WJ, Moss AJ (2008) Inappropriate implantable cardioverter-defibrillator shocks in MADIT II: frequency, mechanisms, predictors, and survival impact. J Am Coll Cardiol 51(14):1357-1365

30. Wathen MS, Sweeney MO, DeGroot PJ, Stark AJ, Koehler JL, Chisner MB, Machado C, Adkisson WO (2001) Shock reduction using antitachycardia pacing for spontaneous rapid ventricular tachycardia in patients with coronary artery disease. Circulation 104(7):796-801

31. Wathen MS, DeGroot PJ, Sweeney MO, Stark AJ, Otterness MF, Adkisson WO, Canby RC, Khalighi K, Machado C, Rubenstein DS, Volosin KJ (2004) Prospective randomized multicenter trial of empirical antitachycardia pacing versus shocks for spontaneous rapid ventricular tachycardia in patients with implantable cardioverter-defibrillators: Pacing Fast Ventricular Tachycardia Reduces Shock Therapies (PainFREE Rx II) trial results. Circulation 110(17):2591-2596

32. Bhavnani SP, Kluger J, Coleman CI, White CM, Guertin D, Shafi NA, Yarlagadda RK, Clyne CA (2010) The prognostic impact of shocks for clinical and induced arrhythmias on morbidity and mortality among patients with implantable cardioverter-defibrillators. Heart Rhythm

33. Wilkoff BL, Cook JR, Epstein AE, Greene HL, Hallstrom AP, Hsia H, Kutalek SP, Sharma A (2002) Dual-chamber pacing or ventricular backup pacing in patients with an implantable defibrillator: the dual chamber and VVI implantable defibrillator (DAVID) trial. JAMA 288(24):3115-3123

34. Blatt JA, Poole JE, Johnson GW, Callans DJ, Raitt MH, Reddy RK, Marchlinski FE, Yee R, Guarnieri T, Talajic M, Wilber DJ, Anderson J, Chung K, Wong WS, Mark DB, Lee KL, Bardy GH (2008) No benefit from defibrillation threshold testing in the SCD-HeFT (Sudden Cardiac Death in Heart Failure Trial). J Am Coll Cardiol 52(7):551-556

35. Cesario D, Bhargava M, Valderrabano M, Fonarow GC, Wilkoff B, Shivkumar K (2004) Azygos vein lead implantation: a novel adjunctive technique for implantable cardioverter defibrillator placement. J Cardiovasc Electrophysiol 15(7):780-783

36. Bristow MR, Saxon LA, Boehmer J, Krueger S, Kass DA, De Marco T, Carson P, DiCarlo L, DeMets D, White BG, DeVries DW, Feldman AM (2004) Cardiac-resynchronization therapy 
with or without an implantable defibrillator in advanced chronic heart failure. N Engl J Med 350(21):2140-2150

37. Cleland JG, Daubert JC, Erdmann E, Freemantle N, Gras D, Kappenberger L, Tavazzi L (2005) The effect of cardiac resynchronization on morbidity and mortality in heart failure. N Engl $\mathrm{J}$ Med 352(15):1539-1549

38. Nayak HM, Verdino RJ, Russo AM, Gerstenfeld EP, Hsia HH, Lin D, Dixit S, Cooper JM, Callans DJ, Marchlinski FE (2008) Ventricular tachycardia storm after initiation of biventricular pacing: incidence, clinical characteristics, management, and outcome. J Cardiovasc Electrophysiol 19(7):708-715

39. Basu Ray I, Fendelander L, Singh JP (2007) Cardiac resynchronization therapy and its potential proarrhythmic effect. Clin Cardiol 30(10):498-502

40. Shukla G, Chaudhry GM, Orlov M, Hoffmeister P, Haffajee C (2005) Potential proarrhythmic effect of biventricular pacing: fact or myth? Heart Rhythm 2(9):951-956

41. Stevenson WG, Wilber DJ, Natale A, Jackman WM, Marchlinski FE, Talbert T, Gonzalez MD, Worley SJ, Daoud EG, Hwang C, Schuger C, Bump TE, Jazayeri M, Tomassoni GF, Kopelman HA, Soejima K, Nakagawa H (2008) Irrigated radiofrequency catheter ablation guided by electroanatomic mapping for recurrent ventricular tachycardia after myocardial infarction: the multicenter thermo cool ventricular tachycardia ablation trial. Circulation 118(25):2773-2782

42. Reddy VY, Reynolds MR, Neuzil P, Richardson AW, Taborsky M, Jongnarangsin K, Kralovec S, Sediva L, Ruskin JN, Josephson ME (2007) Prophylactic catheter ablation for the prevention of defibrillator therapy. N Engl J Med 357(26):2657-2665
43. Aliot EM, Stevenson WG, Almendral-Garrote JM, Bogun F, Calkins CH, Delacretaz E, Della Bella P, Hindricks G, Jais P, Josephson ME, Kautzner J, Kay GN, Kuck KH, Lerman BB, Marchlinski F, Reddy V, Schalij MJ, Schilling R, Soejima K, Wilber D (2009) EHRA/HRS expert consensus on catheter ablation of ventricular arrhythmias: developed in a partnership with the European heart rhythm association (EHRA), a registered branch of the European society of cardiology (ESC), and the heart rhythm society (HRS); in collaboration with the American college of cardiology (ACC) and the American heart association (AHA). Heart Rhythm 6(6):886-933

44. Cesario DA, Vaseghi M, Boyle NG, Fishbein MC, Valderrabano M, Narasimhan C, Wiener I, Shivkumar K (2006) Value of highdensity endocardial and epicardial mapping for catheter ablation of hemodynamically unstable ventricular tachycardia. Heart Rhythm 3(1):1-10

45. Carbucicchio C, Santamaria M, Trevisi N, Maccabelli G, Giraldi F, Fassini G, Riva S, Moltrasio M, Cireddu M, Veglia F, Della Bella P (2008) Catheter ablation for the treatment of electrical storm in patients with implantable cardioverter-defibrillators: short- and long-term outcomes in a prospective single-center study. Circulation 117(4):462-469

46. Doshi RN, Daoud EG, Fellows C, Turk K, Duran A, Hamdan MH, Pires LA (2005) Left ventricular-based cardiac stimulation post AV nodal ablation evaluation (the PAVE study). J Cardiovasc Electrophysiol 16(11):1160-1165 